\title{
Neutrophil-to-lymphocyte ratio as a possible indicator of epicardial adipose tissue in patients undergoing hemodialysis
}

Adalet Ozcicek ${ }^{1}$, Fatih Ozcicek ${ }^{1}$, Gursel Yildiz², Aysu Timuroglu ${ }^{1}$, Levent Demirtas ${ }^{1}$, Mutlu Buyuklu Ufuk Kuyrukluyildiz ${ }^{4}$ Emin Murat Akbas ${ }^{5}$, Ergun Topal ${ }^{3}$, Kultigin Turkmen ${ }^{6}$

\author{
${ }^{1}$ Department of Internal Medicine, School of Medicine, Erzincan University, Erzincan, \\ Turkey \\ 2Department of Nephrology, Atatürk State Hospital, Zonguldak, Turkey \\ ${ }^{3}$ Department Cardiology, School of Medicine, Erzincan University, Erzincan, Turkey \\ ${ }^{4}$ Department of Anesthesiology and Reanimation, School of Medicine, \\ Erzincan University, Erzincan, Turkey \\ ${ }^{5}$ Department of Internal Medicine, Division of Endocrinology and Metabolism, \\ School of Medicine, Erzincan University, Erzincan, Turkey \\ ${ }^{6}$ Department of Internal Medicine, Division of Nephrology, School of Medicine, \\ Erzincan University, Erzincan, Turkey
}

Submitted: 1 February 2015

Accepted: 23 February 2015

Arch Med Sci 2017; 13, 1: 118-123

DOI: 10.5114/aoms.2015.50784

Copyright (c) 2016 Termedia \& Banach

\section{Abstract}

Introduction: Chronic inflammation is a major risk factor in the pathogenesis of cardiovascular disease in end-stage renal disease (ESRD) patients. Epicardial adipose tissue (EAT) is the true visceral fat depot of the heart. The relationship between coronary artery disease and EAT was shown in healthy subjects and ESRD patients. In the present study we aimed to investigate the relationship between EAT and inflammation parameters including neutrophil-to-lymphocyte ratio (NLR) in hemodialysis (HD) patients.

Material and methods: Forty-three HD patients ( 25 females, 18 males; mean age: $64.1 \pm 11.9$ years) receiving $\mathrm{HD}$ and 30 healthy subjects (15 females, 15 males; mean age: $59.1 \pm 10.8$ years) were enrolled in the study. Epicardial adipose tissue measurements were performed by echocardiography.

Results: Neutrophil-to-lymphocyte ratio levels were significantly higher in HD patients than in the healthy control group. Hemodialysis patients were separated into two groups according to their median value of NLR (group 1, NLR $<3.07$ $(n=21)$ and group $2, N L R \geq 3.07(n=22))$. Group 2 patients had significantly higher EAT, C-reactive protein and ferritin levels, while albumin levels were significantly lower in this group. In the bivariate correlation analysis, EAT was positively correlated with NLR $(r=0.600, p<0.001)$ and ferritin $(r=0.485, p=0.001)$ levels. Conclusions: Neutrophil-to-lymphocyte ratio was found to be an independent predictor of EAT in HD patients (odds ratio $=3.178 ; p=0.008$ ). We concluded that this relationship might be attributed to increased inflammation in uremic patients.

Key words: epicardial adipose tissue, neutrophil-to-lymphocyte ratio, inflammation, end-stage renal disease.

\section{Introduction}

Despite the improvements in diagnostic tools and medical applications, cardiovascular diseases (CVD) remain the most common cause

\author{
Corresponding author: \\ Adalet Ozcicek \\ Department \\ of Internal Medicine \\ School of Medicine \\ Erzincan University \\ 24100 Erzincan, Turkey \\ Phone: +90 5052104083 \\ Fax: +90 4462122211 \\ E-mail: draozcicek@hotmail. \\ com
}


of morbidity and mortality in patients with endstage renal disease (ESRD) receiving hemodialysis (HD) $[1,2]$. Beside traditional risk factors including hypertension, diabetes mellitus, dyslipidemia, advanced age and left ventricular hypertrophy (LVH), novel risk factors such as endothelial dysfunction (ED), vascular calcification (VC), oxidative stress, and inflammation are highly prevalent and seem to play a more important role for vascular disease in renal patients compared to healthy subjects [3-7]. Among the risk factors mentioned above, atherosclerosis, inflammation and VC were found to be the most commonly encountered factors in the pathogenesis of CVD in ESRD patients [8, 9].

Epicardial adipose tissue (EAT) originates from the splanchnopleuric mesoderm [10] and is also accepted as the true visceral fat depot of the heart that accounts for approximately $20 \%$ of total heart weight and covers $80 \%$ of the cardiac surfaces, mostly in the grooved segments along the paths of coronary arteries [11-13]. Recent studies have shown a close relationship between coronary artery disease (CAD) and EAT by using multidetector computed tomography (MDCT) and echocardiography in healthy subjects and in patients with high risk of CAD [14-17].

Mazurek et al. [15] concluded that, like abdominal visceral adipose tissue, EAT is also metabolically active because it can secrete proinflammatory cytokines and utilize free fatty acids (FFAs). In recent studies, the authors concluded that EAT acts as an extremely active organ that produces several bioactive adipokines, as well as proinflammatory and proatherogenic cytokines including tumor necrosis factor (TNF)- $\alpha$, interleukin (IL)-6, resistin, visfatin, omentin, leptin, plasminogen activator inhibitor-1 (PAl-1) and angiotensinogen [15, 18-21]. In addition, abdominal subcutaneous fat tissue was also found to be closely associated with inflammation in physiologic conditions such as pregnancy [22].

Turkmen et al. [23] recently demonstrated that EAT is increased in HD and PD patients and this active visceral fat tissue is closely related to malnutrition-inflammation-atherosclerosis/calcification (MIAC) syndrome in this population. Thereafter, the authors also observed the close relation between visceral fat tissue including both epicardial and periaortic fat thickness, inflammation and coronary artery calcification in PD and hemodialysis patients [24].

The ESRD patients also have increased serum levels of inflammatory mediators including high-sensitivity C-reactive protein (hs-CRP), TNF- $\alpha$ and IL-6 [25]. In recent years, neutrophilia and relative lymphocytopenia were shown to be an independent predictor of mortality in patients with acute heart failure [26, 27]. Moreover, neutrophil-to-lymphocyte ratio (NLR) was introduced as a potential marker to determine inflammation in renal and cardiac disorders [28-32].

Neutrophil-to-lymphocyte ratio was also shown as a predictor of long-term mortality in patients who underwent percutaneous coronary intervention [33]. These studies collectively demonstrated the importance of white blood cells including neutrophils and lymphocytes in the pathogenesis of atherosclerosis in the general population.

The exact relationship between vascular calcification and inflammatory parameters including NLR was also demonstrated by the studies done by our group in HD patients [34].

To date in the literature, there has been no study investigating the association between novel inflammatory markers and EAT in HD patients.

In the present study, we aimed to investigate the relationship between EAT, CRP and NLR in ESRD patients receiving HD and to compare these results with others obtained from healthy subjects.

\section{Material and methods}

The study protocol was approved by the Medical Ethics Committee of Erzincan University (School of Medicine, Erzincan, Turkey) in 2012. This was a cross-sectional study involving $43 \mathrm{HD}$ patients receiving $H D$ for $\geq 6$ months in the Hemodialysis Unit of Erzincan University Mengücek Gazi Training and Research Hospital and 30 healthy control subjects. Exclusion criteria were: (i) congestive heart failure; (ii) the presence of active infections; (iii) autoimmune disease. Hemodialysis modality includes conventional 4-h HD three times a week with polysulfone dialyzers. A $250 \mathrm{ml} / \mathrm{min}$ (range: 200-300 $\mathrm{ml} / \mathrm{min}$ ) of mean blood flow rate was obtained during dialysis sessions. Demographic data, medications and dialysis duration of ESRD were recorded.

\section{Biochemical analyses}

Venous blood samples for biochemical analyses were drawn after at least $10 \mathrm{~h}$ of fasting before taking any medication at a single midweek dialysis session. All biochemical analyses were undertaken using an oxidase-based technique at Roche/Hitachi Modular System (Mannheim, Germany) in the Central Biochemistry Laboratory of the Erzincan University School of Medicine, Mengücek Gazi Training and Research Hospital.

\section{Echocardiographic evaluation of EAT}

The echocardiographic parameters were measured before dialysis using transthoracic examina- 
tion in the left lateral decubitus position, including two-dimensional, M-mode, pulsed and color flow Doppler with a GE-Vivid S5 (GE-Vingmed Ultrasound AS, Horten, Norway) machine and a 2.53.5 MHz transducer by an experienced cardiologist blinded to other patients' characteristics. During echocardiographic measurement, a single electrocardiogram (lead II) was recorded simultaneously and data were obtained from the average of three cardiac cycles. Standard 2D, M-mode and Doppler calculations were performed in accordance with American Society of Echocardiography guidelines [35]. The Devereux formula [36] was used to calculate left ventricular mass index (LVMI). Epicardial adipose tissue was defined [37] as the echo-free space between the outer wall of the myocardium and visceral layer of the pericardium on the free wall of the right ventricle at the 2D parasternal long-axis view. Epicardial adipose tissue is recognized as hyperechoic and scattered reflection, typically. We measure EAT on magnified M-mode strips obtained from 2D views with longitudinal cursor beam orientation at end diastole. Thickness is perpendicular to the free wall of the right ventricle and the average of three cardiac cycles' measurement is included.

\section{Statistical analysis}

Clinical and experimental data were analyzed using Statistical Package for Social Sciences for Windows version 21.0 (SPSS Inc., Chicago, Illinois, USA). Descriptive statistics for each variable were determined. Normality of the data distribution was assessed with the Kolmogorov-Smirnov test. Normally distributed data were expressed as mean \pm standard deviation. Results for continuous variables without normal distribution were presented as median (interquartile range (IQR)). A statistically significant difference between the groups was determined by the $\chi^{2}$ test for categorical variables. Nonparametric statistics (Mann-Whitney $U$ ) and parametric statistics (independent sample $t$ test) were all used for continuous variables. Associations between the variables were explored using Spearman's rho test. Binary logistic regression analysis was also performed to define variables associated with EAT. A statistically significant difference was considered when the $p$-value $\leq 0.05$.

\section{Results}

The baseline characteristics of 43 hemodialysis patients (25 females, 18 males; mean age:

Table I. Demographic, clinical and laboratory features of the study groups

\begin{tabular}{|c|c|c|c|}
\hline Parameters & Healthy subjects $(N=30)$ & HD patients $(N=43)$ & $P$-value \\
\hline Female/male* & $15 / 15$ & $25 / 18$ & 0.49 \\
\hline Age [years] ${ }^{\star *}$ & $59.1 \pm 10.8$ & $64.1 \pm 11.9$ & 0.69 \\
\hline BMI $\left[\mathrm{kg} / \mathrm{m}^{2}\right]^{\star *}$ & $26.7 \pm 4.9$ & $25.8 \pm 4.6$ & 0.42 \\
\hline Duration of hemodialysis [months] & - & $63.3 \pm 57.1$ & - \\
\hline $\mathrm{SBP}[\mathrm{mm} \mathrm{Hg}]^{\star \star \star}$ & 115 (107-120) & $130(120-140)$ & $<0.001$ \\
\hline $\mathrm{DBP}[\mathrm{mm} \mathrm{Hg}]^{\star * *}$ & $70(65-76)$ & $80(80-90)$ & $<0.001$ \\
\hline Hemoglobin $[\mathrm{g} / \mathrm{dl}]^{\star *}$ & $14.3 \pm 1.7$ & $11.2 \pm 1.8$ & $<0.001$ \\
\hline Albumin $[\mathrm{g} / \mathrm{dl}]^{\star *}$ & $4.2 \pm 0.2$ & $3.58 \pm 0.3$ & $<0.001$ \\
\hline Ferritin $[\mathrm{ng} / \mathrm{ml}]$ & - & $578(287-1200)$ & - \\
\hline Calcium [mg/dl] & - & $8.46 \pm 1.54$ & - \\
\hline Phosphorus [mg/dl] & - & $5.00 \pm 1.55$ & - \\
\hline Parathormone [pg/ml] & - & $589(284-1078)$ & - \\
\hline $\mathrm{CRP}[\mathrm{mg} / \mathrm{dll}]^{* * *}$ & $0.33(0.22-0.53)$ & $0.85(0.44-1.29)$ & $<0.001$ \\
\hline$N L R^{* * *}$ & $1.85(1.57-2.31)$ & $3.07(1.78-3.82)$ & 0.001 \\
\hline $\mathrm{EAT}[\mathrm{mm}]^{\star \star \star}$ & $5.5(4-7)$ & $8(5-10)$ & 0.001 \\
\hline $\operatorname{LVM}[\mathrm{g}]^{\star \star \star}$ & $85(79-94)$ & $208(193-233)$ & $<0.001$ \\
\hline LVMI $\left[\mathrm{g} / \mathrm{m}^{2}\right]^{* * *}$ & $48(44-54)$ & 119 (111-139) & $<0.001$ \\
\hline $\mathrm{EF}(\%)^{* * *}$ & $67(65-67)$ & $64(60-66)$ & $<0.001$ \\
\hline
\end{tabular}

${ }^{*} \chi^{2},{ }^{* *}$ independent sample $t$ test (mean $\pm S D$ ), ${ }^{* * *}$ Mann-Whitney $U$ test [median (IQR)]. BMI - body mass index, SBP - systolic blood pressure, DBP - diastolic blood pressure, CRP - C-reactive protein, NLR - neutrophil-to-lymphocyte ratio, EAT-epicardial adipose tissue, $L V M$ - left ventricular mass, LVMI - left ventricular mass index, EF- ejection fraction. 
Table II. Demographic, clinical and laboratory features of HD patients according to NLR groups

\begin{tabular}{|c|c|c|c|}
\hline Parameters & $N L R<3.07(N=21)$ & $N L R \geq 3.07(N=22)$ & $P$-value \\
\hline Age [years] ${ }^{*}$ & $63.3 \pm 13.8$ & $64.9 \pm 9.8$ & 0.62 \\
\hline BMI $\left[\mathrm{kg} / \mathrm{m}^{2}\right]^{*}$ & $25.2 \pm 4.4$ & $26.4 \pm 4.9$ & 0.40 \\
\hline $\mathrm{SBP}[\mathrm{mm} \mathrm{Hg}]^{\star *}$ & $135(120-140)$ & $130(120-140)$ & 0.45 \\
\hline $\mathrm{DBP}[\mathrm{mm} \mathrm{Hg}]^{\star *}$ & $80(75-92)$ & $80(77-86)$ & 0.74 \\
\hline Hemoglobin $[\mathrm{mg} / \mathrm{dl}]^{*}$ & $11.5 \pm 1.9$ & $11 \pm 1.7$ & 0.36 \\
\hline Albumin $[\mathrm{g} / \mathrm{dl}]^{\star}$ & $3.69 \pm 0.3$ & $3.47 \pm 0.3$ & 0.037 \\
\hline Calcium $[\mathrm{mg} / \mathrm{dll}]^{*}$ & $8.87 \pm 0.7$ & $8.36 \pm 0.9$ & 0.16 \\
\hline Phosphorus [mg/dl] ${ }^{*}$ & $5.3 \pm 1.5$ & $4.82 \pm 1.6$ & 0.44 \\
\hline Parathormone $[\mathrm{pg} / \mathrm{ml}]^{\star \star}$ & $370(257-948)$ & $822(410-1138)$ & 0.14 \\
\hline Ferritin $[\mathrm{ng} / \mathrm{ml}]^{\star \star}$ & $343(216-574)$ & $1003(575-1456)$ & 0.002 \\
\hline $\mathrm{CRP}[\mathrm{mg} / \mathrm{dll}]^{* *}$ & $0.5(0.3-1.1)$ & $1(0.6-1.6)$ & 0.033 \\
\hline$E F(\%)^{\star \star}$ & $64(60-65)$ & $62(60-66)$ & 0.90 \\
\hline EAT $[\mathrm{mm}]^{* *}$ & $6(5-7.5)$ & $9(8-11.2)$ & 0.001 \\
\hline $\operatorname{LVM}[g]^{\star \star}$ & $201(193-235)$ & $220(195-233)$ & 0.42 \\
\hline LVMI $\left[\mathrm{g} / \mathrm{m}^{2}\right]^{\star \star}$ & $115(112-136)$ & $119(108-154)$ & 0.84 \\
\hline
\end{tabular}

${ }^{\star}$ Independent sample t test (mean \pm SD), ${ }^{* *}$ Mann-Whitney $U$ test [median (IQR)]. BMI - body mass index, SBP - systolic blood pressure, $D B P$ - diastolic blood pressure, CRP - C-reactive protein, NLR - neutrophil-to-lymphocyte ratio, EAT - epicardial adipose tissue, LVM - left ventricular mass, LVMI - left ventricular mass index, EF- ejection fraction.

$64.1 \pm 11.9$ years) and 30 healthy control subjects (15 females, 15 males; mean age, $59.1 \pm 10.8$ years) are shown in Table I. The etiology of ESRD patients was diabetic nephropathy $(n=10,23.3 \%)$, chronic glomerulonephritis ( $n=4,9.2 \%)$, hypertensive nephropathy ( $n=19,44.2 \%)$, polycystic kidney disease ( $n=2,4.7 \%)$, nephrolithiasis ( $n=4,9.2 \%$ ), chronic tubulointerstitial nephritis ( $n=2,4.7 \%$ ), and unknown $(n=2,4.7 \%)$. There were no significant differences in terms of age, gender and body mass index (BMI) between HD patients and healthy subjects. The healthy control group had significantly lower systolic blood pressure, diastolic blood pressure, EAT, LVM, LVMI, CRP and NLR, while ejection fraction (EF), hemoglobin and albumin levels were significantly higher in this group.

Neutrophil-to-lymphocyte ratio levels were significantly higher in HD patients than in the healthy control group (Table I). HD patients were separated into two groups according to their median value of NLR (group $1, \mathrm{NLR}<3.07(n=21)$ and group $2, \operatorname{NLR} \geq 3.07(n=22)$ ). There were no differences with respect to the following variables between these two groups: age, BMI, systolic blood pressure, diastolic blood pressure, EF, LVM, LVMI, serum levels of hemoglobin, calcium, phosphorus and parathormone (Table II). Group 2 patients had significantly higher EAT, CRP and ferritin levels, while albumin levels were significantly lower in this group (Table II). In the bivariate cor-
Table III. Predictors of EAT in HD patients

\begin{tabular}{|lcccc|}
\hline Parameters & $P$-value & Odds ratio & \multicolumn{2}{c|}{$95 \% \mathrm{Cl}$} \\
\hline NLR & 0.008 & 3.178 & 1.351 & 7.475 \\
\hline CRP & 0.394 & 0.713 & 0.328 & 1.550 \\
\hline Albumin & 0.563 & 0.342 & 0.009 & 12.919 \\
\hline BMI & 0.164 & 1.157 & 0.942 & 1.420 \\
\hline
\end{tabular}

$B M I$ - body mass index, CRP - C-reactive protein, NLR - neutrophilto-lymphocyte ratio, EAT-epicardial adipose tissue, $\mathrm{Cl}$-confidence interval.

relation analysis in HD patients, EAT was positively correlated with NLR $(r=0.600, p<0.001)$ and ferritin $(r=0.485, p=0.001)$ levels.

Binary logistic regression analysis was also performed to define variables associated with EAT (Table III). The BMI, CRP, albumin and NLR levels were included in this model. The NLR levels were found to be an independent predictor of EAT.

\section{Discussion}

There were four main findings of the present study. First, NLR levels were significantly higher in HD patients than in the healthy control group. Second, HD patients who had high inflammatory status were also found to have significantly higher EAT, CRP and ferritin levels and significantly lower serum albumin levels when compared to HD patients with low inflammatory status. Third, in the 
bivariate correlation analysis, EAT was positively correlated with NLR in HD patients. Lastly, in the binary logistic regression analysis, NLR levels were found to be independently associated with EAT in these patients. To our knowledge, this is the first study to demonstrate the positive association between EAT and NLR in ESRD patients receiving hemodialysis.

In recent years, researchers have analyzed a large panel of biomarkers to fully characterize the relation between inflammation and CVD, including C-reactive protein, IL-1 $\beta, \mathrm{IL}-6$, and TNF- $\alpha$ in chronic kidney disease and ESRD patients [3841]. In addition, several interesting new biomarkers were considered to better describe inflammation in this population. In this regard, NLR is a potential marker for inflammation in cardiac and non-cardiac disorders $[28,29,42]$ that was also shown to be a predictor of long-term mortality in patients who underwent percutaneous coronary intervention [33]. The authors demonstrated that NLR could predict inflammation in ESRD patients and in renal transplant patients [30, 41]. In accordance with previous studies, in the present study we found that HD patients had higher inflammatory biomarkers including NLR and CRP compared to healthy subjects. Additionally, HD patients who had higher NLR also had higher CRP and ferritin and lower albumin levels.

Epicardial adipose tissue is the true visceral fat depot of the heart that accounts for approximately $20 \%$ of total heart weight and covers $80 \%$ of the cardiac surfaces, and is mostly in the grooved segments along the paths of coronary arteries [1113]. Recent studies showed a close relationship between CAD and EAT using MDCT and echocardiography in healthy subjects and patients at a high risk of CAD [14-17]. Although the pathophysiologic role of EAT is not clear to date, the researchers suggest that EAT may act as an extremely active organ that produces several bioactive adipokines as well as proinflammatory and proatherogenic cytokines such as TNF- $\alpha$, monocyte chemotactic protein (MCP-1), IL-6 and resistin [15, 18-21]. In a recent study, the authors found a relationship between MIAC syndrome and EAT in ESRD patients receiving hemodialysis or peritoneal dialysis [23].

In the present study, among HD patients, those who had higher NLR and CRP also had higher EAT.

This could be attributed to increased inflammatory cytokines that are secreted by EAT in this population. The present study had some limitations. First, this was a cross-sectional analysis of HD patients focusing on the relationship between NLR, CRP and EAT. Second, the sample size was relatively small. Third, since EAT has a three dimensional distribution, two dimensional echocardiographic measurements may not be sufficient to assess the total amount. This was not a prospective con- trolled study, so we can not draw cause-and-effect relationships from our findings.

In conclusion, the relation between inflammation and adipose tissue is extremely complex in ESRD patients. However, simple calculation of NLR can predict EAT in this population. Taken together, traditional and non-traditional risk factors including chronic low grade inflammation and increased EAT might contribute to cardiovascular disease and the markedly increased mortality in patients with ESRD. Hence, further randomized and controlled studies evaluating the relationship between visceral adipose tissue and NLR in ESRD patients are needed.

\section{Conflict of interest}

The authors declare no conflict of interest.

\section{References}

1. United States Renal Data System. USRDS 2006 Annual Data Report: Atlas of End-Stage Renal Disease in United States. National Institute of Health. Bethesda: National Institute of Diabetes and Digestive and Kidney Diseases 2006.

2. Franczyk-Skora B, Gluba A, Banach M, Rysz J. Treatment of non-ST-elevation myocardial infarction and ST-elevation myocardial infarction in patients with chronic kidney disease. Arch Med Sci 2013; 9: 1019-27.

3. Parfrey PS, Foley RN, Harnett JD, Kent GM, Murray DC, Barre PE. Outcome and risk factors for left ventricular disorders in chronic uraemia. Nephrol Dial Transplant 1996; 11: 1277-85.

4. Cheung AK, Sarnak MJ, Yan G, et al. Atherosclerotic cardiovascular disease risks in chronic hemodialysis patients. Kidney Int 2000; 58: 353-62.

5. Muntner P, He J, Astor BC, Folsom AR, Coresh J. Tradition$\mathrm{al}$ and nontraditional risk factors predict coronary heart disease in chronic kidney disease: results from the atherosclerosis risk in communities study. J Am Soc Nephrol 2005; 16: 529-38.

6. Himmelfarb J, Stenvinkel P, Ikizler TA, Hakim RM. The elephant in uremia: oxidant stress as a unifying concept of cardiovascular disease in uremia. Kidney Int 2002; 62: 1524-38.

7. Franczyk-Skora B, Gluba A, Olszewski R, Banach M, Rysz J. Heart function disturbances in chronic kidney disease - echocardiographic indices. Arch Med Sci 2014; 10: 1109-16.

8. Parfrey PS, Foley RN, Harnett JD, Kent GM, Murray D, Barre PE. Outcome and risk factors of ischemic heart disease in chronic uremia. Kidney Int 1996; 49: 1428-34.

9. Collins AJ. Cardiovascular mortality in end-stage renal disease. Am J Med Sci 2003; 325: 163-7.

10. Ho E, Shimada Y. Formation of the epicardium studied with the scanning electron microscope. Dev Biol 1978; 66: 579-85.

11. lacobellis G, Corradi D, Sharma AM. Epicardial adipose tissue: anatomic, biomolecular and clinical relationships with the heart. Nat Clin Pract Cardiovasc Med 2005; 2: 536-43.

12. Corradi D, Maestri R, Callegari S, et al. The ventricular epicardial fat is related to the myocardial mass in normal, ischemic and hypertrophic hearts. Cardiovasc Pathol 2004; 13: 313-6. 
13. Shirani J, Berezowski K, Roberts WC. Quantitative measurement of normal and excessive (cor adiposum) subepicardial adipose tissue, its clinical significance, and its effect on electrocardiographic QRS voltage. Am J Cardiol 1995; 76: 414-8.

14. Djaberi R, Schuijf JD, van Werkhoven JM, Nucifora G, Jukema JW, Bax JJ. Relation of epicardial adipose tissue to coronary atherosclerosis. Am J Cardiol 2008; 102: 1602-7.

15. Mazurek T, Zhang L, Zalewski A, et al. Human epicardial adipose tissue is a source of inflammatory mediators. Circulation 2003; 108: 2460-6.

16. Park MJ, Jung JI, Oh YS, Youn HJ. Assessment of epicardial fat volume with threshold-based 3-dimensional segmentation in CT: comparison with the 2-dimensional short axis-based method. Korean Circ J 2010; 40: 328-33.

17. Eroglu S, Sade LE, Yildirir A, et al. Epicardial adipose tissue thickness by echocardiography is a marker for the presence and severity of coronary artery disease. Nutr Metab Cardiovasc Dis 2009; 19: 211-7.

18. Baker AR, Silva NF, Quinn DW, et al. Human epicardial adipose tissue expresses a pathogenic profile of adipocytokines in patients with cardiovascular disease. Cardiovasc Diabetol 2006; 5: 1.

19. Kremen J, Dolinkova M, Krajickova J, et al. Increased subcutaneous and epicardial adipose tissue production of proinflammatory cytokines in cardiac surgery patients: possible role in postoperative insulin resistance. J Clin Endocrinol Metab 2006; 91: 4620-7.

20. Cheng KH, Chu CS, Lee KT, et al. Adipocytokines and proinflammatory mediators from abdominal and epicardial adipose tissue in patients with coronary artery disease. Int J Obes (Lond) 2008; 32: 268-74.

21. Fain JN, Sacks HS, Buehrer B, et al. Identification of omentin mRNA in human epicardial adipose tissue: comparison to omentin in subcutaneous, internal mammary artery periadventitial and visceral abdominal depots. Int J Obes (Lond) 2008; 32: 810-5.

22. Kosus N, Kosus A, Turhan N. Relation between abdominal subcutaneous fat tissue thickness and inflammatory markers during pregnancy. Arch Med Sci 2014; 10 739-45.

23. Turkmen K, Kayikcioglu H, Ozbek O, et al. The relation ship between epicardial adipose tissue and malnutrition, inflammation, atherosclerosis/calcification syndrome in ESRD patients. Clin J Am Soc Nephrol 2011; 6: $1920-5$.

24. Turkmen K, Tonbul HZ, Erdur FM, et al. Peri-aortic fat tissue and malnutrition-inflammation-atherosclerosis/ calcification syndrome in end-stage renal disease patients. Int Urol Nephrol 2013; 45: 857-67.

25. Stenvinkel P, Ketteler M, Johnson RJ, et al. IL-10, IL-6, and TNF-alpha: central factors in the altered cytokine network of uremia - the good, the bad, and the ugly. Kidney Int 2005; 67: 1216-33.

26. Arruda-Olson AM, Reeder GS, Bell MR, Weston SA, Roger VL. Neutrophilia predicts death and heart failure after myocardial infarction: a community-based study. Circ Cardiovasc Qual Outcomes 2009; 2: 656-62.

27. Rudiger A, Burckhardt OA, Harpes P, Muller SA, Follath $F$. The relative lymphocyte count on hospital admission is a risk factor for long-term mortality in patients with acute heart failure. Am J Emerg Med 2006; 24: 451-4.

28. Tamhane UU, Aneja S, Montgomery D, Rogers EK, Eagle KA, Gurm HS. Association between admission neutrophil to lymphocyte ratio and outcomes in pa- tients with acute coronary syndrome. Am J Cardiol 2008; 102: 653-7.

29. Nunez J, Nunez E, Bodi V, et al. Usefulness of the neutrophil to lymphocyte ratio in predicting long-term mortality in ST segment elevation myocardial infarction. Am J Cardiol 2008; 101: 747-52.

30. Turkmen K, Guney I, Yerlikaya FH, Tonbul HZ. The relationship between neutrophil-to-lymphocyte ratio and inflammation in end-stage renal disease patients. Ren Fail 2012; 34: 155-9.

31. Ozyurtlu F, Yavuz V, Cetin N, Acet H, Ayhan E, Isik T. The association between coronary slow flow and platelet distribution width among patients with stable angina pectoris. Postep Kardiol Interw 2014; 10: 161-5.

32. Akbas EM, Demirtas L, Ozcicek A, et al. Association of epicardial adipose tissue, neutrophil-to-lymphocyte ratio and platelet-to-lymphocyte ratio with diabetic nephropathy. Int J Clin Exp Med 2014; 7: 1794-801.

33. Duffy BK, Gurm HS, Rajagopal V, Gupta R, Ellis SG, Bhatt DL. Usefulness of an elevated neutrophil to lymphocyte ratio in predicting long-term mortality after percutaneous coronary intervention. Am J Cardiol 2006; 97: 993-6.

34. Turkmen K, Ozcicek F, Ozcicek A, Akbas EM, Erdur FM, Tonbul HZ. The relationship between neutrophil-to-lymphocyte ratio and vascular calcification in end-stage renal disease patients. Hemodial Int 2014; 18: 47-53.

35. Quinones MA, Otto CM, Stoddard M, Waggoner A, Zoghbi WA. Recommendations for quantification of Doppler echocardiography: a report from the Doppler Ouantification Task Force of the Nomenclature and Standards Committee of the American Society of Echocardiography. J Am Soc Echocardiogr 2002; 15: 167-84.

36. Devereux RB, Alonso DR, Lutas EM, et al. Echocardiographic assessment of left ventricular hypertrophy: comparison to necropsy findings. Am J Cardiol 1986; 57: 450-8.

37. Iacobellis G, Ribaudo MC, Assael F, et al. Echocardiographic epicardial adipose tissue is related to anthropometric and clinical parameters of metabolic syndrome: a new indicator of cardiovascular risk. J Clin Endocrinol Metab 2003; 88: 5163-8.

38. Stenvinkel P, Carrero JJ, Axelsson J, Lindholm B, Heimburger O, Massy Z. Emerging biomarkers for evaluating cardiovascular risk in the chronic kidney disease patient: how do new pieces fit into the uremic puzzle? Clin J Am Soc Nephrol 2008; 3: 505-21.

39. Turkmen K, Gorgulu N, Uysal M, et al. Fetuin-A, inflammation, and coronary artery calcification in hemodialysis patients. Indian J Nephrol 2011; 21: 90-4.

40. Turkmen K, Erdur FM, Guney I, et al. Relationship between pasma pentraxin-3, neutrophil-to-lymphocyte ratio, and atherosclerosis in renal transplant patients. Cardiorenal Med 2012; 2: 298-307.

41. Turkmen K, Tonbul HZ, Toker A, et al. The relationship between oxidative stress, inflammation, and atherosclerosis in renal transplant and end-stage renal disease patients. Ren Fail 2012; 34: 1229-37.

42. Walsh SR, Cook EJ, Goulder F, Justin TA, Keeling NJ. Neutrophil-lymphocyte ratio as a prognostic factor in colorectal cancer. J Surg Oncol 2005; 91: 181-4. 